\title{
REVIEWS
}

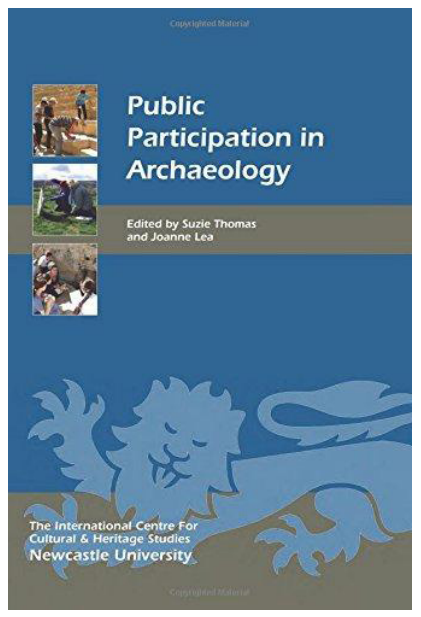

Amanda HARVEY

\section{Public participation in Archaeology}

[Edited by Suzie Thomas \& Joanne Lea]

Boydell \& Brewer ISBN: 9781843838975

225 pages

"Is there anything even left to discover?" is a question I am often asked by people when talk of jobs and backgrounds come up. Each and every time, my heart sinks. It is a moment that reinforces the point that we, as stewards of cultural heritage, play an important role in helping to educate and engage our communities about cultural heritage and archaeology and communicate how they are both relevant to our lives. To preface, I am an archaeologist and an educator currently working in an informal science education institution- though I feel most archaeologists play both roles these days out of necessity and responsibility of practice. My personal byline has always been "If we are doing this work for these communities but these communities do not have a role in it, do not know of it, or do not care about it... Then what is the point?". My sentiments are reiterated in the preface of this volume by Peter Stone. He tells of a time when he was young and thought we already knew everything we needed to know about the Romans. Through school programmes and engagement as a child, he realized that actively engaging the public in archaeology and history helps them to better grow from it which in turn helps us to know more about 
ourselves and shape our future. This is not to say that communities need to be taught their own cultural heritage or archaeologists necessarily assume that they do not already know it, but rather that archaeologists need to work with local communities to help meet their needs and provide support.

This volume is part of the Heritage Matters series, a self-described "series of edited and single-authored volumes that confront the cultural heritage sector as we face the global challenges of the twenty-first century", from the International Centre for Cultural and Heritage Studies (ICCHS) at Newcastle University. The theme for this particular volume is 'public participation in archaeology', which means it could refer to a broad category covering a number of topics within archaeology. This volume seeks to address four main topical areas or venues for public participation in archaeology: 1- Public Participation in Archaeology: International Models, 2- Public Participation in Archaeology through Education, 3- Public Participation in Archaeology through Tourism, and 4Public Participation in Archaeology through Site Management. The editors have created a volume that has the potential to reach the public they seek to engage and serve by providing a good overview of how public participation can be addressed. Additionally, it is well-rounded in its examples and considerate of the avenues of participation in archaeology that most people may come into contact with at some point in their lives. The pieces within this volume are engaging, thoughtfully incorporated, and well-written to suit audiences interested in archaeology and community heritage. The readers could be considered amateurs or professionals-the ultimate in aiming to achieve public participation and engagement. This also serves to meet a goal of the authors to embrace the multiple definitions of 'public' (Thomas and Lea 2014, 2) and what it means for archaeology.

The editors, Thomas and Lea, are both highly experienced in the realm of public archaeology. Thomas is, as of the volume's printing, a lecturer in Museology at the University of Helsinki and formerly served as a Community Archaeology Support Officer at the Council for British Archaeology. Lea is, as of the volume's printing, an educator with the Trillium Lakelands District School Board in Ontario, Canada and formerly, among many achievements, served 
as Chair of the Public Education and Outreach Committee for the Canadian Archaeological Association. Not only do they both bring a wealth of information and expertise to the table but the chapter authors themselves represent an international cohort of experts within archaeology and public participation.

To begin with, Thomas and Lea provide a comprehensive summary of their plan for the volume. This includes defining what they mean by 'public' ("amateur" vs. "professional") and also how the sections fit together within the volume. Additionally, they provide a review of debates and discussion on the concept of public participation in archaeology. Acknowledging differing opinions and providing the reader, whatever their expertise level, with the understanding that this volume does not exist in a vacuum is a very important action, especially in a piece designed for public engagement. For example, there are concerns as to what the Open Access movement may mean for the protection of archaeological sites as well as what it means for who has access in the sense of 1 ) knowledge of how to find the data and information, 2) use the technology, and 3) who actually has the access to technology, like a computer, to actually get to it (Hess and Ostrom 2007, 11; Mukherjee 2010, 127; Thomas and Lea 2014, 3). Finally, their introduction closes with acknowledging the limitations of the volume in relation to global and economic situations but being hopeful that it will serve as "an impetus to all those involved in public or community archaeology, as volunteers or as practitioners or as both, to continue to reflect on and record their practices, and to contribute to the growing global debate" (Thomas and Lea 2014, 5).

Speaking of global debates, the first section opens with a piece from Moussouri that asks what do we actually mean when we say 'public participation' and what are models in public participation that actually show promise of working? This chapter makes excellent points, really stressing that no one model of public engagement will work for all settings and that there is no one best model to work from. That said, I am not entirely sure why this chapter is included in the section on 'international models'. Moussouri's general discussion leading up to her case studies provides an excellent context of developing and designing public engagement activities. This could easily be included in the second section focusing on public 
participation through education. Regardless of where it is located in this volume, the editors skillfully saw the importance in its content. The other chapters in the section cover Great Britain, Ireland, the Netherlands, and Argentina. All provide excellent models and case studies for public participation in their respective countries and regions. However, while this section is on international models, it does not provide a representative example of areas around the world. Yet the focus is on international highlights of models that have been used and what worked in each from a selection of areas which is helpful to provide examples of practice.

The following section highlights public participation through education and looks at the inclusion of archaeology as a means for incorporating history and cultural heritage into STEM education and engagement for K-12 educators and learners in Canada, the UK, the USA, and Jordan. The chapters provide a solid set of viewpoints on a range of ways of thinking about archaeology in education - from forming relationships with educators to developing programme models to examining some of the reasons why some people value and teach archaeology and cultural heritage - for education or for profit? The reader should also note that these examples of educational techniques (i.e. inquiry-based lessons) are often accepted within both the formal and informal educational communities as reliable, established educational models. This provides the reader with a great foundation on which to potentially grow their own plans and methods for engagement of archaeological topics by the public and in traditional classroom settings. The section leads with a chapter by MacDonald and provides insight into the benefits and methods of creating, developing, and then maintaining systemic relationships where archaeologists engage with educators and learners via partnerships such as the Society for American Archaeology and developing archaeology programmes, particularly in Canada. While it may depend on the programme goal, many times archaeologists want the relationships we create to go beyond a one-time engagement. For example, working to instill a curriculum and/or practice of archaeology will function best when maintained and repeated for more than one session. A curriculum that incorporates archaeology helps to give the learner a better context of why and how archaeology is used and to embrace the multidisciplinary opportunities that incorporating archaeology 
allows. MacDonald highlights this use of archaeology as a tool to engage students in a multidisciplinary model to incorporate topics from "physical education to science, maths, writing, research and the arts" while also "lending itself to cooperative learning and group work; it is experiential and hands on" (MacDonald 2014, 73). This also leads well into the following chapters that discuss programmes designed for students that focus on inquiry-based methods. Through examples of successful case studies, the reader can start to examine how they may want to design and implement their own to help meet the learning and engagement needs of educators and students in their communities. The final chapter also helps to link this section on education with the following section on tourism. Badran examines how educators in Jordan view cultural heritages sites and what they mean to them - are these sites for knowledge or for profit from tourism? - and how does that impact how cultural heritage is included into textbooks and taught in schools. For example, is it because it has meaning to you on a cultural connection level or is it because it brings in tourism which helps to support your community and its economy?

This leads to the third section on tourism that comprises chapters that cover the impacts on designing engagement with politics and cultural needs in mind. Programmes are only impactful and effective if they can be used and valued by their communities. If the design does not work for a community, then it will not help to encourage participation and engagement with their cultural heritage. Additionally, governments, media coverage of availability of access, and even media coverage focused on just the presence of sites and monuments play a major role in whether or not communities even know if they can have access or if they even want access. For example, Corbishley and Jorayev point out that this type of situation is occurring in Turkmenistan where the media focuses on more nationalistic endeavours of promoting 'the great past' and do not focus necessarily on specific periods or monuments (Corbishley and Jorayev 2014, 127). The section concludes that access to sites through tourism, as noted by Aranda and Carmargo, is "not only an important revenue generator for archaeological conservation but also a medium for public education and heritage interpretation" (Aranda and Carmargo 2014, 139). For example, this engagement of tourism and the community is "ultimately the way forward for 
Mexican archaeology" according to Aranda and Carmargo, with the "good" and "bad" that comes from it $(2014,139)$. They also point out that the government actively encourages this engagement in archaeology through many initiatives including government and private industry alliances, heritage tourism, and an online presence including social media, all of which the government has found to be beneficial. Throughout the chapter, Aranda and Carmargo discuss these different initiatives and their impacts. In the internet access component, Aranda and Carmargo's discussion relates back to Thomas and Lea's discussion on the concerns for Open Access. While a lot of this information and data from the Mexican government is available online, many of the indigenous groups, for whom it is their cultural identity, do not have access due to limited technology availability.

The fourth and final section looks at Thomas and Lea's final venue for public participation in archaeology - sites and conservation. The chapters all highlight different aspects of management from local support and care to larger management schemes and government policies. Abu-Khafajah interviewed locals to learn more about what their heritage sites mean to them and their opinions on how they are managed. She discusses how even terminology has connotations and meaning to the community. For example, they see "archaeology" as colonial intervention vs. "heritage" as a community term for their "collective and individual identities" (Abu-Khafajah 2014, 150). So in this case, working with the community provided an opportunity to give these participants a voice. On the opposite end, Sarac explores new legislation and site management from the Turkish government - technically a voice of the government unlike Abu-Khafajah's voice of the people. Not to say that the words from a government are bad. It is just a differing angle of looking at how sites and conservation are seen. The other pieces in this section also provide insights as to how other countries explore the angle from which sites and conservation are managed from local management of sites to national policy.

Honestly, this is an excellent volume of work and there is not much, if any, fault to be found. As a text to provide initial discussion on the venues of public participation in archaeology, it is adeptly organized and planned to provide a reader at almost 
any degree of experience in archaeology a solid foundation on how public or community archaeology is being shaped today. One area that some reviewers might comment on is a slight lack of worldwide geographic representation in all of the sections as, in some of them, the selected pieces were limited mostly to case studies and references from Europe or North America - not to say that that is a small coverage area in the slightest. The volume did have a diverse representation of the topic areas from around the globe overall. However, a full diverse spectrum of worldwide representation along with the topics already provided would make for a several thousand pages long volume. A point to consider is that community or public archaeology is still relatively new in many areas around the world and not even an option in others still. So the lack of representation of educational participation may be representative of the current lack or small number of participant programmes from other regions. Additionally, the case studies and chapters that did examine areas outside of Europe and North America, particularly Corbishley and Jorayev, noted the importance of providing programme plans and work that coincide with local communities' needs and cultural backgrounds, so perhaps these other regions have communities where it would not work or be beneficial to them. For example, rather than making a project in Ancient Merv (Turkmenistan) fit within the outlines of educational programmes of Europe, they designed and developed a programme that worked for the people who it was designed for and would be engaging with it. This is something to reflect upon in the future for archaeologists and communities to work towards. Another point to consider is that worldwide geographical representation does not seem like it was an intended goal for the editors for this volume. So it makes sense that they would focus more on topic coverage. It is not possible to be all-encompassing and all-representative at all times in all pieces. I feel that the editors met their goals as outlined in their introduction.

As discussed, this volume flows very well as a result of strategic placement of chapters, quality of content, and the holistic work of the editors and chapter contributors. The pieces did not feel redundant and each helped to build upon the next and to connect chapter to chapter and section to section. There is broad coverage of topic areas within the overarching theme of public participation 
in archaeology. I also feel that the editors provided insightful pieces of work that are both representative of the people working in the field and well-written, accessible, and engaging to the public.

\section{Bibliography}

Bell, P, Lewenstein, B, Shouse, A W, and Feder, M A (eds), 2009. Learning Science in Informal Environments: People, Places, and Pursuits. The National Academies Press, Washington, DC.

Hess, C, and Ostrom, E, 2007. Understanding Knowledge as a Commons, The MIT Press, Cambridge, MA.

Mukherjee, B, 2010. Scholarly Communication in Library and Information Services, Chandos Publishing, Oxford. 